\section{SOI: $1.1 /$ TAS $\quad$ DOI: $10.15863 /$ TAS International Scientific Journal Theoretical \& Applied Science}

\author{
p-ISSN: 2308-4944 (print) e-ISSN: 2409-0085 (online) \\ Year: $2016 \quad$ Issue: 4 Volume: 36 \\ Published: $30.04 .2016 \quad \underline{\text { http://T-Science.org }}$
}

Sanobar Narzikulovna Akbarova

$\mathrm{PhD}$,

Tashkent Pediatric Medical institute,

Uzbekistan

sanobarakbarova@tashpmi.uz

Khatira Dadabayevna Aymetova

Senior teacher,

Tashkent Pediatric Medical institute,

Uzbekistan

SECTION 21. Pedagogics. Psychology. Innovation in the field of education.

\title{
THE PROBLEMS OF FAMILY UPBRINGING IN UZBEKISTAN
}

Abstract: Issues of education in the family is important in the formation of harmonious personality-rounded member of society. We have studied the influence of the factor of the education degree in parenting skills of their children. The survey involved 50 parents of different professions. It was found that the level of education impacts to the formation of the parents as competent educator.

Key words: pedagogy, education, higher education secondary school, family, parents.

Language: Russian

Citation: Akbarova SN, Aymetova KD (2016) THE PROBLEMS OF FAMILY UPBRINGING IN UZBEKISTAN. ISJ Theoretical \& Applied Science, 04 (36): 121-124.

Soi: http://s-o-i.org/1.1/TAS-04-36-19 Doi: cross's http://dx.doi.org/10.15863/TAS.2016.04.36.19

УДК-37.042

ВОПРОСЫ СЕМЕЙНОГО ВОСПИТАНИЯ В УЗБЕКИСТАНЕ

Аннотация: Вопросы воспитания в семье являются важными в становлении личности, гармоничного и всесторонне развитого члена общества. Нами было изучено влияние фактора степени образования и компетентности родителей в вопросах воспитания своих детей. В анкетировании участвовали 50 родителей разных профессий. Было выявлено, что степень образования сопутствует в становлении родителей компетентными воспитателями.

Ключевые слова: педагогика, воспитание, высшее образование, среднее образование, семья, родители.

Вопросы воспитания своеобразно формировались на территории Средней Азии на протяжении нескольких веков. Древнейшие педагогические взгляды были отражены в книге “Авесто" [1], Каръан, Хадис, “Диване Хикмат" Ходжи Ахмеда Ясави [2], "Кутадгу билиг” Юсуфа Баласагуния [3], “О смысле разума" Фараби [4], «Диван Луга тат-Турк” Махмуда алКашгари [5], “Хибатул-хакойик” Ахмада Югнаки [6], a также многочисленных произведениях Алишера Наваи, Амира Темура, Улугбека, Бабура, Ибн Сины $[7,8]$ и других.

Вопросы воспитания всегда были и остаются в центре внимания в институтах социализации в Узбекистане. Задача формирования гармонично развитого поколения была поднята на уровень государственной политики. Эта политика опиралась на многовековые ценности узбекского народа, его стремление к совершенному поколению [9]. Наиболее эффективная фаза человеческого воспитания и обучения начинается в дошкольном возрасте. Упущения в этом возрасте невозможно компенсировать, так как разрыв в развитии и восприимчивости к обучению между детьми, получившими полноценное дошкольное обучение, и не получившими, как правило, только возрастает. По данным статистики в 2005 г. охват дошкольными воспитательными заведениями по Узбекистану составлял всего лишь $19 \%$ от общего числа детей с 3 -х до 6 лет включительно [10]. Следовательно, воспитание основной части детей происходит в окружении семьи.

Родители играют огромную роль в воспитании детей. По данным исследований и наблюдений детских домов, 70\% хулиганов, заброшенных молодых, которые совершили преступные действия, являлись детьми неблагоприятных семей [11].

Как известно, каждый родитель воспитывает собственных детей, следуя традиций воспитания [12], направленных к ним со стороны своих родителей. В связи с этим возникает вопрос: 


\begin{tabular}{|c|c|c|c|c|c|c|}
\hline Impact Factor: & $\begin{array}{l}\text { ISRA (India) } \\
\text { ISI (Dubai, UAE } \\
\text { GIF (Australia) } \\
\text { JIF }\end{array}$ & $\begin{array}{l}=1.344 \\
=0.829 \\
=0.564 \\
=1.500\end{array}$ & $\begin{array}{l}\text { SIS (USA) } \\
\text { PИНЦ (Russia) } \\
\text { ESJI (KZ) } \\
\text { SJIF (Morocco) }\end{array}$ & $\begin{array}{l}=0.912 \\
=0.234 \\
=1.042 \\
=2.031\end{array}$ & $\begin{array}{l}\text { ICV (Poland) } \\
\text { PIF (India) } \\
\text { IBI (India) }\end{array}$ & $\begin{array}{l}=6.630 \\
=1.940 \\
=4.260\end{array}$ \\
\hline
\end{tabular}

«Достаточным ли является опыт, передаваемый через поколение в процессе воспитания всесторонне развитой личности?». Нашей целью является изучить факторы развития, уровни компетентности, по вопросам воспитания детей у родителей различного возраста и профессий.

Был применен метод анкетирования из 10 вопросов. В исследовании участвовали 50 родителей узбекской национальности города Ташкента. Сравнительный анализ данных был сделан разделяя опрошенных родителей на группы учитывая степень полученного образования (родители с высшим образованием и средним образованием) и разного пола. Среди ответов интересными оказались на следующий заданный вопрос: "Можете ли вы вежливо попросить вашего ребенка о чём-то, в ущерб приказывания сделать чего-то?" На этот вопрос (1-вопрос) среди матерей с высшим образованием, только 4\% ответили “нет” (Рис.1), и такие же ответы были отмечены у $27 \%$ матерей со средним образованием (Рис.2), т. е., на много больше. Также, $33 \%$ отцов со средним образованием заявили, что не могут попросить своих детей о чем-то, это означает, они предпочитают приказывать, нежели попросить вежливо (Рис.3).

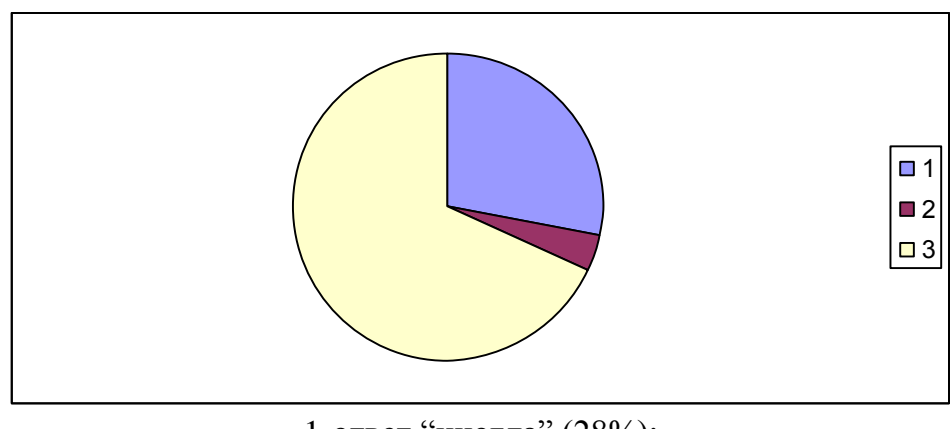

1-ответ “иногда" (28\%);

2-“нет”(4\%); 3-“да"(68\%)

Рисунок 1 - Ответы на 1-вопрос женщин (с выс. обр.).

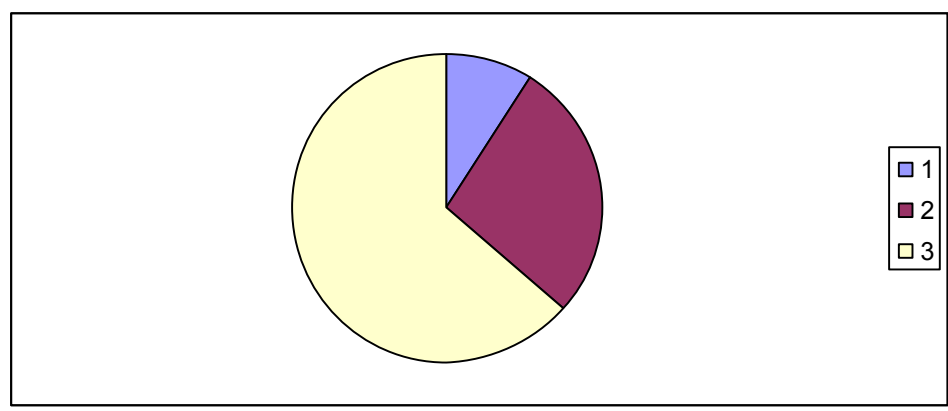

1 - ответ "иногда" (9\%);

2-“нет”(27\%); 3-“да"(64\%)

Рисунок 2 - Ответы на 1-вопрос женщин (с сред. обр.).

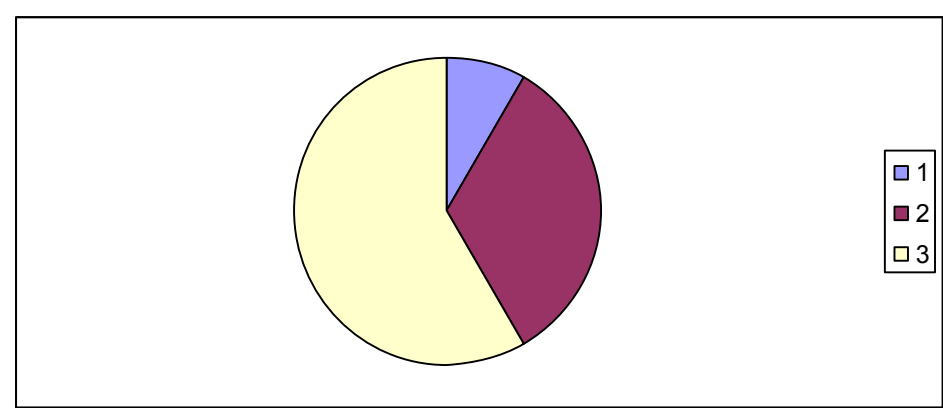

1- ответ "иногда" (8\%);

2-“нет” (33\%); 3-“да"(59\%)

Рисунок 3 - Ответы на 1-вопрос мужчин (с сред. обр.). 
Это означает, что в стиле воспитания у родителей со средним образованием преобладает авторитаризм. Обращение к ребёнку осуществляется, в основном, в тоне приказывания.

Следующий вопрос звучал так "Ваш ребёнок совершил проступок. Обдумываете ли вы, что это результат вашего воспитания данное ребёнку?” Ответы на этот вопрос также отличались среди матерей с высшим и средним образованием. На этот вопрос положительно ответили 56\% женщин с высшим образованием (Рис.4) и 82\% женщин со средним образованием (Рис.5). Результаты говорят о том, что большинство женщин со средним образованием считают, что проступки своих детей являются плодами своих же ошибок в воспитани, а значит осознают, что в некоторых вопросах воспитания они считают себя не компетентными.

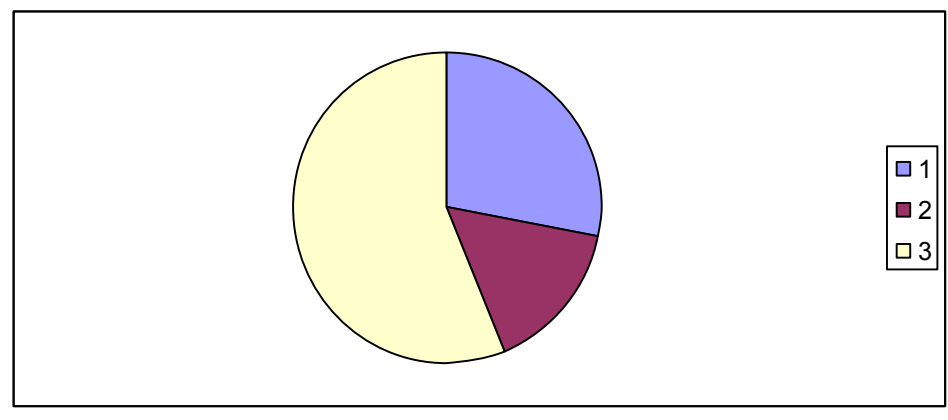

1-ответ "иногда" (28\%);

2-“нет”(16\%); 3-“да"(56\%)

Рисунок 4 - Ответы на 2-вопрос женщин (с выс. обр.).

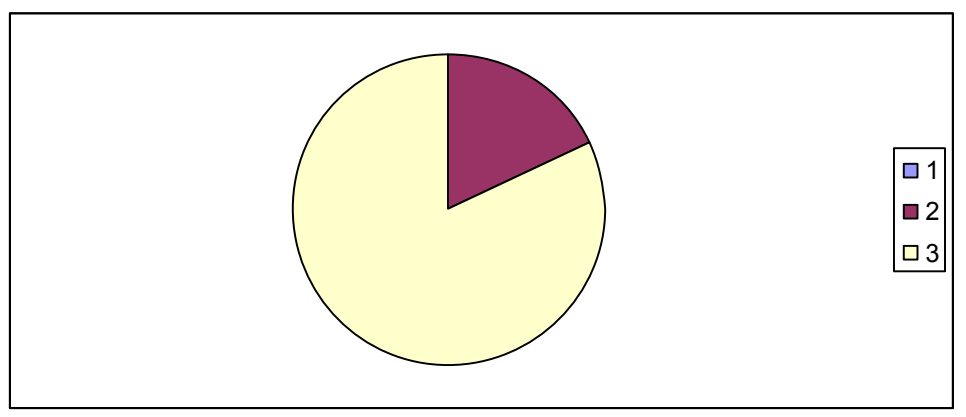

1-ответ "иногда" $(0 \%)$;

2-“нет”(18\%); 3-“да”( $82 \%)$

Рисунок 5 - Ответы на 2-вопрос женщин (с сред. обр.).

На следующем этапе анализа мы подсчитали общие баллы анкетирования. Ответ “да" был оценен 2 баллами, "иногда" 1 бал и ответ "нет" ноль балла. Чем больше баллов, тем больше компетентность в воспитании. Участники опроса с высшим образованием опередили в общем среднем балле $(16,5)$ родителей со средним образованием $(14,4)$.

Вывод: высшее образование влияет на повышение компетентности в вопросах воспитания молодого поколения. Процесс получения высшего образования формирует личность зрелого воспитателя. Мы можем полагать, что, получение соответствующих знаний по педагогике, психологии и другим смежным предметам, а также практическое наблюдение за процессом воспитания студентов со стороны педагогов вузов способствует становлению личности более компетентного воспитателя.

Но, среди населения Узбекистана большая часть имеет только среднее образования. Тогда, каким образом, они воспитывают своих детей? Этот вопрос также является важным. Только 45\% их опрошенных родителей со средним образованием твердили, что используют средства массовой информации и смотрят программы посвященные вопросам воспитания детей. Мы считаем, что решение этой проблемы является актуальным. Поскольку, основная часть подростающего поколения находится под влиянием воспитания родителей, главным образом, именно имеющее только среднее образование. 


\begin{tabular}{|c|c|c|c|c|c|c|}
\hline Impact Factor: & $\begin{array}{l}\text { ISRA (India) } \\
\text { ISI (Dubai, UAE } \\
\text { GIF (Australia) } \\
\text { JIF }\end{array}$ & $\begin{array}{l}=1.344 \\
=0.829 \\
=0.564 \\
=1.500\end{array}$ & $\begin{array}{l}\text { SIS (USA) } \\
\text { PИНЦ (Russia) } \\
\text { ESJI (KZ) } \\
\text { SJIF (Morocco) }\end{array}$ & $\begin{array}{l}=0.912 \\
=0.234 \\
=1.042 \\
=2.031\end{array}$ & $\begin{array}{l}\text { ICV (Poland) } \\
\text { PIF (India) } \\
\text { IBI (India) }\end{array}$ & $\begin{array}{l}=6.630 \\
=1.940 \\
=4.260\end{array}$ \\
\hline
\end{tabular}

В целом, мы считаем, что процесс семейного воспитания до сих пор происходит хаотично. Каждый родитель воспитывает своих детей по своему. Иногда за нехваткой знаний о воспитании следуют сожаления, слёзы, семейные проблемы, стресс, депрессия и прочие [13]. Пока вопросами профессионального воспитания занимается только система непрерывного образования. В этих вопросах наше государство возлагает большую ответственность на государственные учрежления такие как: детские сады, средние школы, колледжи, лицеи, институты и университеты. Но всё же, проблемы воспитания в семейном окружении должны быть решены с учетом многовекового опыта наших выдающихся предков, и обменом достижений и передового опыта в сфере педагогики стран зарубежья.

\section{References:}

1. Khasanboev Z, Turakulov K, Khaydarov ME, Khasanbaeva OU (2008) Pedagogika fanidan izoxli luғat. Toshkent, 2008, 238 p.

2. Mekhti S (2007) Put' Yasavi i ego rol' v razvitii islama V Tsental'noy Azii // Vestnik Chelyabinskogo gosudarstvennogo universiteta: zhurnal. - Chelyabinsk, 2007. - № 23. - pp. 150-159.

3. (2016)

Available: www.directeducation.ru/powing-1533-1.html (Accessed: 10.04.2016).

4. (2012) SINA-BALASAGUNI C. A. L. F. I. B. N. MIROVAYa PEDAGOGIChESKAYa MYSL" V KONTEKSTE SRAVNENIYa: KONFUTSIY-AL" FARABI-IBN SINABALASAGUNI //International Perspectives on Education. - 2012. - pp. 439.

5. Makhmud al-Kashgari (2005) Divan Luga tatTurk/ Perevod, predislovie i kommentarii Z.A.M. Auezovoy; indksy sostavleny R.Ermersom. -Almaty: Dayk-Press, 2005. $1288 \mathrm{p}$.

6. Dzhuraev RK, Mardonov SK (2008) Pedagogicheskie idei velikikh mysliteley Vostoka-osnova podgotovki pedagogicheskikh kadrov //Obrazovanie cherez vsyu zhizn': nepreryvnoe obrazovanie $\mathrm{v}$ interesakh ustoychivogo razvitiya. - 2008. - T. 6.
7. Rakhimov CR (1964) Pedagogicheskie idei Abu Ali Ibn Siny. Avtoref. dis. ped. Nauk. Tashkent 1964.

8. Ishkuvvatov V (2008) Nizomiy nomidagi TDPU dotsenti, F.Sanaev Nizomiy nomidagi TDPU talabasi. "Kadimgi Khoramda ta"lim va tarbiya", Zhurnal Pedagogik ta"lim. 2008 yil 3son 97-99 p.

9. Fayzullaeva NS (2011) Pedagogika i psikhologiya. Uchebnoe posobie. -Tashkent, 2011. 164 p.

10. (2016)

Available: http://www.humandevelopment.uz/ru/courses/d etail.php?COURSE_ID=5\&LESSON_ID=62 (Accessed: 10.04.2016).

11. Zhonalieva S (2008) Nizomiy nomidagi TDPU talabasi, "Nobop oilalarga izhtimoiypsikhologik erdam ky̆rsatish uslublari”, Zhurnal Pedagogik ta"lim. 2008 yil 1-son 149-152 p.

12. Egamberdieva N (2008) Nizomiy nomidagi TDPU dotsenti, "Milliy mentalitetning izhtimoiy-psikhologik asoslari", Zhurnal Pedagogik ta"lim. 2008 yil 1-son 8-10 p.

13. Merenkov AV (2013) Tendentsiya izmeneniya semeynogo vospitaniya $\mathrm{v}$ sovremennom obshchestve // Sotsiologicheskoe issledovanie. - 2013. -№ 2. - pp. 101-109. 